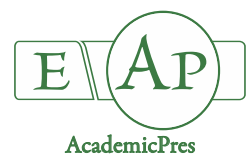

\title{
Comparison of the Chemical Composition of Essential Oils Isolated from Two Thyme (Thymus vulgaris L.) Cultivars
}

\author{
Aneta WESOŁOWSKA ${ }^{1 *}$, Dorota JADCZAK ${ }^{2}$ \\ ${ }^{1}$ West Pomeranian University of Technology, Szczecin, Faculty of Chemical Technology and Engineering, Department of Organic and \\ Physical Chemistry, Piastów Ave. 42, 71-065 Szczecin, Poland; Aneta.Wesolowska@zut.edu.pl ('corresponding author) \\ ${ }^{2}$ West Pomeranian University of Technology, Szczecin, Faculty of Environmental Management and Agriculture, Department of \\ Horticulture, Papieża PawtaVI No 1,71-459 Szczecin, Poland; Dorota.Jadczak@zut.edu.pl
}

\begin{abstract}
In the studies conducted in 2016-2017, the chemical composition of the essential oils isolated from the herb of two thyme (Thymus vulgaris L.) cultivars was investigated by gas chromatography-mass spectrometry (GC-MS). The GC-MS analyses of the volatile oils of T. vulgaris L. cv. 'English Winter' and cv. 'Summer Thyme de Provence' led to the identification of 80 and 73 constituents, respectively. The main components found in the oil of 'English Winter' cultivar were thymol (44.97 and $38.06 \%$ in 2016 and 2017, respectively), p-cymene (7.61 and 10.34\%), $\gamma$-terpinene (7.08 and 6.66\%) and carvacrol (5.11 and $8.27 \%)$. Similarly, thymol (36.82 and 37.32\%), p-cymene (15.73 and $11.20 \%)$, $\gamma$-terpinene (5.34 and $11.09 \%$ ) and carvacrol (6.50 and 5.35\%) dominated in the essential oil of 'Summer Thyme de Provence' cultivar. However, the higher content of thymol was noted for cultivar 'English Winter', while cultivar 'Summer Thyme de Provence' was richer in p-cymene.
\end{abstract}

Keywords: chemotypes; essential oil content; garden thyme; hydrodistillation; linalool

\section{Introduction}

Thyme (Thymus vulgaris L.), an aromatic perennial subshrub belonging to the Lamiaceae family, is commonly known for its therapeutic properties since ancient times. The whole plant as well as its different extracts is used in medicine, cosmetic and food industry (Sharafzadeh et al., 2010). Thymi herba has expectorant, antitussive, antibroncholytic, antispasmodic, carminative and diuretic properties (Marzec et al., 2010; Al-Asmari et al., 2017). Therefore the consumption of thyme extracts is recommended all over the world (Sharafzadeh et al., 2010). The aerial parts of Thymus are also used as a condiment in meat industry (to flavor meats such as rabbit, boar and lamb) and in the production of herb wine and liqueurs (Cornara et al., 2000; Marzec et al., 2010).

The beneficial properties of thyme are a consequence of the presence of thymol and carvacrol in its essential oil (Agili, 2014). These major phenolic compounds have antioxidant, antimicrobial and antifungal properties (Alizadeh, 2013). Anti-worm, antiseptic and antispasmodic activities of thyme volatile oil have been also well documented (Marino et al., 1999). Thymi aetheroleum has been reported to be in world's top ten of essential oils used as food additive (Marzec et al., 2010; Agili, 2014). It is mainly applied in the production of candies, herbal teas and ice tea (Carlen et al., 2010).

Chemical composition of thyme essential oil is well known. Thymol, $\gamma$-terpinene, p-cymene, carvacrol, linalool, $\alpha$-pinene, borneol, 1,8-cineole, geraniol, caryophyllene as well as limonen, terpinen-4-ol and trans-sabinene hydrate are reported to be its main constituents (Marzec et al., 2010; Sharafzadeh et al., 2010; Satyal et al., 2016). Based on the predominance of particular monoterpeneoids in the volatile oil six different chemotypes of $T$. vulgaris have been identified (Thompson et al., 2003; Torras et al., 2007; Chizzola et al., 2008): phenolic chemotypes (thymol and carvacrol) and non-phenolic chemotypes (geraniol, $\alpha$ terpineol, linalool and trans-thujan-4-ol/terpinen-4-ol). Interestingly, in Spanish thyme another chemotype has been detected: 1,8-cineole (Guillen and Manzanos, 1998). Moreover, T. vulgaris collected in France represented the linalool chemotype, while geraniol chemotype has been described as characteristic for thyme in Serbia (Satyal et al., 2016). The most valuable for industrial purposes is Thymus vulgaris which contains from 20 to $80 \%$ of thymol (Marzec et al., 2010). 
830

The availability of various chemotypes and the production of new cultivars have resulted in a great variation in the essential oil composition and aroma among thyme species. Because the processing industry needs high quality raw material, it is important for thyme producers to have high quality cultivars with a good level of homogeneity (Carlen et al., 2010).

Nowadays, seeds of Thymus vulgaris $\mathrm{L}$. are offered to sale by many companies. Most of the cultivars are not chemically characterized.

Therefore, the aim of the study conducted in 2016-2017 was to determine the chemical composition of two commercial thyme cultivars: 'English Winter' and 'Summer Thyme de Provence'. To the best of our knowledge, no one has characterized chemically these two cultivars.

\section{Materials and Methods}

\section{Plantmaterial}

The field experiment was conducted at the Horticultural Experimental Station in Dołuje (northwestern Poland), which belongs to the West Pomeranian University of Technology in Szczecin. The experiment was performed on sandy clay soil characterized by low waterholding capacity. The field was prepared according to agrotechnique proper for thyme cultivation. Mineral fertilization was quantified according to the results of the chemical analysis of the soil samples and supplemented to the recommended for thyme level of $60 \mathrm{~g} \mathrm{~N}$ and $50 \mathrm{~g} \mathrm{~K}_{2} \mathrm{O}$ per $10 \mathrm{~m}^{2}$. In the first year, nitrogen fertilizer was applied in two doses: $1 / 2$ - before sowing and $1 / 2$ - three weeks after sowing, potassium fertilizer - once (before sowing). In the second and third year of cultivation, $50 \mathrm{~g} \mathrm{~K}_{2} \mathrm{O}\left(\right.$ per $10 \mathrm{~m}^{2}$ ) and $100 \mathrm{~g} \mathrm{P}_{2} \mathrm{O}_{5}$ (per $10 \mathrm{~m}^{2}$ ) were applied on early spring. Nitrogen fertilizer was applied in two doses: $1 / 2$ - after plant vegetation and $1 / 2$ - after harvest. During plant growth, standard cultivation treatments were performed, including weeding, soil loosening and watering, whenever necessary.

Commercial seeds purchased from the seed company Chiltern Seeds (United Kingdom) were used in the present study. The cultivars were as follows: 'English Winter' and 'Summer Thyme de Provence'. Seeds were sown on seedbed at the second decade of March 2015. In the same year, the obtained seedlings were planted into the open field in the last decade of May, with spacing of $30 \times 20 \mathrm{~cm}$. The plants were grown in experimental plots with an area of $1.44 \mathrm{~m}^{2}$ $\left(1.2 \times 1.2 \mathrm{~m}^{2}\right)$, in four replications.
For laboratory analyses a herb from two- and three-year old plants was collected during flowering (harvest dates: 9 June 2016 and 10 June 2017 - 'English Winter' cultivar and 24 May 2016 and 30 May 2017 - 'Summer Thyme de Provence' cultivar). A $100 \mathrm{~g}$ samples, from each experimental plot $(4 \times 100 \mathrm{~g})$, were taken. Subsequently, the samples of each cultivar were combined, mixed and dried in a shady and well ventilated place at room temperature (drying room). The dried plants were cut into small pieces and stored in a dry and cool place until analysis. Representative samples (200 g, each year) were used for essential oil isolation.

The weather conditions (the average values of daily temperature $\left({ }^{\circ} \mathrm{C}\right)$, rainfall (mm), insolation (hours)) during the period of Thymus vulgaris L. cultivation are shown in Table 1.

\section{Determination of essential oil content}

Thirty grams of dried aerial parts of thyme (each cultivar separately) in a $1000 \mathrm{~mL}$ round-bottomed flask along with $400 \mathrm{~mL}$ of distilled water was subjected to hydrodistillation in a Clevenger-type apparatus for 2 hours, according to the method recommended by European Pharmacopoeia (2010). The measurements of the distillation time started after the falling of the first drop of distillate. After 2 hours of distillation, the volume of the oil collected into the calibrated tube of apparatus was read.

Obtained essential oils were dried over anhydrous sodium sulphate and, after filtration, stored in dark sealed vials at $4{ }^{\circ} \mathrm{C}$ until GC-MS analysis. Tree replicates were carried out. Essential oil content was calculated based on dry weight of plant material and expressed as $\% \mathrm{v} / \mathrm{w}$ (volume of essential oil per $100 \mathrm{~g}$ of plant material) in Table 2 .

Gas Chromatography-Mass Spectrometry analysis of the essential oils

The identification of the chemical constituents of the essential oil samples was performed on an HP 6890 gas chromatograph equipped with a HP-5MS capillary column $(30 \mathrm{~m} \times 0.25 \mathrm{~mm}$; film thickness $0.25 \mu \mathrm{m})$ and directly coupled with HP 5973 Mass Selective Detector.

Helium was used as a carrier gas at a flow rate of $1.0 \mathrm{~mL}$ $\mathrm{min}^{-1}$. Samples of $1 \mu \mathrm{L}$ (30 mg of oil dissolved in $1.5 \mathrm{~mL}$ of dichloromethane) were injected with a split ratio of 5:1. The injector and the transfer line were kept at $280^{\circ} \mathrm{C}$. The ion source temperature was $230^{\circ} \mathrm{C}$.

Table 1. Meteorological data from the period of Thymus vulgaris L. growing in 2016-2017

\begin{tabular}{|c|c|c|c|c|c|c|c|c|c|c|c|c|}
\hline \multirow{2}{*}{ Years } & \multicolumn{12}{|c|}{ Months } \\
\hline & I & II & III & IV & $\mathrm{V}$ & VI & VII & VIII & IX & $\mathrm{X}$ & $\mathrm{XI}$ & XII \\
\hline \multicolumn{13}{|c|}{ Mean daily air temperature, ${ }^{\circ} \mathrm{C}$} \\
\hline 2016 & -0.9 & 3.7 & 4.3 & 8.8 & 15.7 & 18.5 & 19.0 & 17.8 & 16.8 & 8.6 & $-{ }^{*}$ & 3.1 \\
\hline 2017 & 2.5 & -2.1 & 0.5 & 6.8 & 13.5 & 16.8 & 17.2 & 17.9 & 13.3 & 11.0 & 5.7 & 3.4 \\
\hline \multicolumn{13}{|c|}{ Total rainfall $(\mathrm{mm})$} \\
\hline 2016 & 27.0 & 40.6 & 28.1 & 20.2 & 18.9 & 69.0 & 50.0 & 47.8 & 18.3 & 55.3 & - & 57.5 \\
\hline 2017 & 68.6 & 5.7 & 35.8 & 42.3 & 99.2 & 118.1 & 182.4 & 45.4 & 31.6 & 65.1 & 74.7 & 34.8 \\
\hline \multicolumn{13}{|c|}{ Insolation $(\mathrm{h})$} \\
\hline 2016 & 56.4 & 62.3 & 117.0 & 200.4 & 287.8 & 267.7 & 196.4 & 217.8 & 256.0 & 43.1 & - & 48.7 \\
\hline 2017 & 30.3 & 116.6 & 147.4 & 150.8 & 321.9 & 215.5 & 189.7 & 224.5 & 126.4 & 102.2 & 50.2 & 31.4 \\
\hline
\end{tabular}


Table 2. Essential oil content in Thymus vulgaris L. cultivars in 2016-2017

\begin{tabular}{cccc}
\hline \multirow{2}{*}{ Cultivar } & \multicolumn{2}{c}{ Essential oil content $(\% \mathrm{v} / \mathrm{w})$} & \multirow{2}{*}{ Mean } \\
\cline { 2 - 3 } & 2016 & 2017 & 1.40 \\
\hline 'English Winter' & 2.29 & 0.51 & 0.86 \\
'Summer Thyme de Provence' & 1.08 & 0.64 & 1.13 \\
Mean & 1.69 & 0.58 & 0.257 \\
\hline LSD $_{\alpha=0.05}$ & 1.17 & n.s. & \\
\hline
\end{tabular}

The column temperature was initially kept at $40{ }^{\circ} \mathrm{C}$ for $5 \mathrm{~min}$, then increased to $60^{\circ} \mathrm{C}$ at a rate of $30^{\circ} \mathrm{C} \mathrm{min}{ }^{-1}$, next to $230^{\circ} \mathrm{C}$ at a rate of $6{ }^{\circ} \mathrm{C} \mathrm{min}^{-1}$ (kept constant for $10 \mathrm{~min}$ ), and then increased to a final temperature of $280^{\circ} \mathrm{C}$ at a rate of $30^{\circ} \mathrm{C} \mathrm{min}{ }^{-1}$. The oven was held at this temperature for 5 minutes. Mass spectra were taken at $70 \mathrm{eV}$ with a mass scan range of 40-550 amu. Scan speed: 2.94/s.

Solvent delay was $4 \mathrm{~min}$. The total running time for a single sample was about 51 minutes.

The relative percentage of the essential oil constituents was evaluated from the total peak area (TIC) by apparatus software.

\section{Identification of essential oil constituents}

Essential oil constituents were identified by comparison of their retention indices (relative to $\mathrm{n}$-alkanes $\mathrm{C}_{7}-\mathrm{C}_{30}$ (Supelco, Bellefonte, PA, USA) on HP-5MS column) with those reported in NIST Chemistry WebBook (http://webbook.nist.gov/chemistry/) and literature (Adams, 2007; Babushok et al., 2011). Further identification was made by comparison of their mass spectra with those stored in the Wiley NBS75K.L and NIST/EPA/NIH (2002 and 2014 version) mass spectral libraries, as well as by comparison of their mass spectra with authentic compounds available in our laboratory (thymol, carvacrol, p-cymene and $\beta$-pinene, purchased from SigmaAldrich and Fluka).

\section{Statistical analysis}

The results of the study (Table 2 and 4) were subjected to an analysis of variance which was performed with AWAR software, made by the Department of Agrometeorology and Applied Informatics, Institute of Soil Science and Plant Cultivation in Puławy, Poland (Filipiak and Wilkos, 1995). The means of two years were separated using the Tukey's Studentized Range Test at $\mathrm{p}=0.05$. The statistical analysis of the results given in Table 4 was conducted for constituents of content greater than $1 \%$ of essential oil.

\section{Results and Discussion}

The yield of essential oils obtained by hydrodistillation from the dried aerial parts of two thyme cultivars ranged from 0.86 to $1.40 \%$ (v/w) (Table 2). Statistical analysis of the results obtained showed significant differences in the content of essential oil in the plant material obtained in 2016 (two-year-old plants) and on average for both years of the study. The higher content of essential oil was noted for 'English Winter' cultivar.

The content of essential oil in dry thyme herb varied from $0.32 \%$ (Ozguven and Tansi, 1998) to 4.90\% (Carlen et al., 2010). The European Pharmacopoeia 7.0 (2010) prescribes a minimum yield of $1.2 \%$. Our results are generally comparable with cited literature. However, in the regard of pharmacopoeial requirements, only the percentage yield of essential oil obtained from two-year-old plants of 'English Winter' cultivar was found to be in conformity with European Pharmacopoeia standards.

The percentage composition of the obtained essential oils as well as the main classes of the identified constituents is shown in Table 3. The volatile components are listed in the order of their elution from a HP-5 MS column.

In the two Thymus vulgaris L. essential oils, a total of ninety-three different compounds were identified: 80 for 'English Winter' cultivar (99.44\% of the total oil) and 73 for 'Summer Thyme de Provence' cultivar (99.38\% of the oil).

The main constituents found in the oil of 'English Winter' were thymol (44.97 and 38.06\% in 2016 and 2017 , respectively), p-cymene (7.61 and 10.34\%), $\gamma$-terpinene (7.08 and 6.66\%) and carvacrol (5.11 and 8.27\%). Other components accounted for more than $2 \%$ were $\beta$ caryophyllene (3.50 and 4.18\%), linalool (2.77 and 3.68\%), $\alpha$-terpinene (2.27 and $1.77 \%)$, thymol methyl ether $(2.62$ and $0.29 \%$ ) and carvacrol methyl ether (2.12 and $1.50 \%)$. The volatile oil of 'Summer Thyme de Provence' was also rich in thymol (36.82 and 37.32\%), p-cymene (15.73 and $11.20 \%), \gamma$-terpinene (5.34 and $11.09 \%)$ and carvacrol (6.50 and $5.35 \%)$. Other abundant constituents were $\beta$ caryophyllene (4.06 and 3.75\%), linalool (3.09 and 2.46\%), borneol (2.23 and 1.22\%), caryophyllene oxide (2.06 and $1.33 \%)$ and $\alpha$-terpinene (1.67 and $2.49 \%$ ).

Generally, the main compounds identified in the oils of two thyme cultivars were the same. Although, the higher concentration of thymol (38.06-44.97\%) was observed in the oil isolated from 'English Winter' cultivar, while oil obtained from 'Summer Thyme de Provence'cultivar was richer in p-cymene (11.20-15.73\%). Moreover, transgeraniol $(0.15-0.15 \%)$ was found only in 'English Winter' oil, whereas trace amount of phellandral (0.02-0.06\%) we detected only in the oil of 'Summer Thyme de Provence'.

Oxygenated monoterpenes (58.67-64.01\% in 'English Winter' and $52.39-55.17 \%$ in 'Summer Thyme de Provence') and monoterpene hydrocarbons (22.41-23.16\% in 'English Winter' and 27.45-30.02\% in 'Summer Thyme de Provence') were shown to be the main group of constituents in both the oils, whereas oxygenated diterpenes were present in very low amounts $0.05 \%$ in 'English Winter' and $0.08 \%$ in 'Summer Thyme the Provence') (Table 3).

The statistical analysis of the results presented in Table 4 indicated that the studied essential oils, regardless of the year of cultivation, were characterized by the highest content of thymol - from 36.82 to $44.97 \%$. 
Table 3. Percentage composition of the essential oils of two T. vulgaris L. cultivars

\begin{tabular}{|c|c|c|c|c|c|c|}
\hline \multirow{3}{*}{ No. } & \multirow{3}{*}{ Compounds ${ }^{a}$} & \multirow{3}{*}{$\mathrm{RI}^{\mathrm{b}}$} & \multicolumn{4}{|c|}{ Cultivar } \\
\hline & & & \multicolumn{2}{|c|}{ 'English Winter' } & \multicolumn{2}{|c|}{ 'Summer Thyme' } \\
\hline & & & 2016 & 2017 & 2016 & 2017 \\
\hline 1. & Methyl $\alpha$-methylbutanoate & 783 & 0.31 & 0.25 & 0.20 & 0.12 \\
\hline 2. & $\alpha$-Thujene & 925 & 0.36 & 0.31 & 0.16 & 0.52 \\
\hline 3. & $\alpha$-Pinene & 931 & 0.93 & 0.68 & 0.97 & 0.80 \\
\hline 4. & Camphene & 946 & 0.36 & 0.51 & 0.88 & 0.34 \\
\hline 5. & $\beta$-Pinene & 975 & 0.28 & 0.20 & 0.17 & 0.24 \\
\hline 6. & 1-Octen-3-ol & 977 & 1.03 & 0.85 & 0.52 & 0.34 \\
\hline 7. & 3-Octanone & 984 & $\because$ & 0.08 & 0.06 & 0.05 \\
\hline 8. & $\beta$-Myrcene & 989 & 1.75 & 1.18 & 1.06 & 1.67 \\
\hline 9. & 3-Octanol & 994 & 0.09 & 0.23 & 0.10 & - \\
\hline 10. & $\alpha$-Phellandrene & 1002 & 0.37 & 0.25 & 0.22 & 0.32 \\
\hline 11. & 3-Carene & 1008 & 0.15 & 0.12 & 0.10 & 0.13 \\
\hline 12. & $\alpha$-Terpinene & 1015 & 2.27 & 1.77 & 1.67 & 2.49 \\
\hline 13. & p-Cymene & 1024 & 7.61 & 10.34 & 15.73 & 11.20 \\
\hline 14. & D-Limonene & 1027 & 0.69 & 0.82 & 0.89 & 0.82 \\
\hline 15. & Eucalyptol & 1030 & 1.24 & 1.22 & 1.48 & 1.26 \\
\hline 16. & (Z)-B-Ocimene & 1036 & 0.09 & - & - & - \\
\hline 17. & (E)-B-Ocimene & 1047 & 0.09 & - & - & 0.10 \\
\hline 18. & $\gamma$-Terpinene & 1058 & 7.08 & 6.66 & 5.34 & 11.09 \\
\hline 19. & cis-Sabinene hydrate & 1066 & 1.00 & 0.69 & 0.28 & 0.92 \\
\hline 20. & $\alpha$-Terpinolene & 1087 & 0.38 & 0.32 & 0.26 & 0.30 \\
\hline 21. & Linalool & 1098 & 2.77 & 3.68 & 3.09 & 2.46 \\
\hline 22. & trans-Sabinene hydrate & 1104 & 0.24 & - & - & - \\
\hline 23. & $\beta$-Thujone & 1110 & - & 0.05 & - & - \\
\hline 24. & (Z)- $\beta$-Terpineol & 1121 & - & 0.15 & 0.07 & 0.10 \\
\hline 25. & Pinocarveol & 1139 & - & 0.08 & 0.05 & - \\
\hline 26. & Camphor & 1145 & 0.22 & 0.57 & 0.86 & - \\
\hline 27. & (+)-2-Bornanone & 1151 & 0.38 & . & - & - \\
\hline 28. & Borneol & 1166 & 0.99 & 1.78 & 2.23 & 1.22 \\
\hline 29. & Terpinen-4-ol & 1177 & 0.66 & 1.27 & 1.00 & 1.22 \\
\hline 30. & p-Cymen-8-ol & 1186 & 0.78 & 0.12 & 0.13 & 0.14 \\
\hline 31. & $\alpha$-Terpineol & 1190 & 0.13 & 0.15 & 0.20 & 0.13 \\
\hline 32. & Myrtenal & 1196 & 0.41 & 0.27 & 0.15 & 0.21 \\
\hline 33. & trans-Dihydrocarvone & 1204 & 0.11 & - & - & - \\
\hline 34. & trans-Carveol & 1216 & - & 0.05 & - & - \\
\hline 35. & Thymol methyl ether & 1234 & 2.62 & 0.29 & 0.17 & 0.14 \\
\hline 36. & Carvacrol methyl ether & 1243 & 2.12 & 1.50 & 1.65 & 1.61 \\
\hline 37. & Thymoquinone & 1257 & 0.09 & 0.09 & 0.23 & 0.11 \\
\hline 38. & Phellandral & 1277 & - & - & 0.06 & 0.02 \\
\hline 39. & trans-Geraniol & 1263 & 0.15 & 0.16 & - & - \\
\hline 40. & Bornyl acetate & 1284 & 0.02 & 0.22 & 0.20 & 0.18 \\
\hline 41. & Thymol & 1297 & 44.97 & 38.06 & 36.82 & 37.32 \\
\hline 42. & Carvacrol & 1303 & 5.11 & 8.27 & 6.50 & 5.35 \\
\hline 43. & $\alpha$-Cubebene & 1353 & 0.25 & 0.14 & 0.04 & 0.08 \\
\hline 44. & Ylangene & 1374 & 0.07 & 0.07 & 0.08 & 0.03 \\
\hline 45. & $\alpha$-Copaene & 1379 & 0.18 & 0.22 & 0.29 & 0.10 \\
\hline 46. & $\beta$-Bourbonene & 1389 & 0.07 & 0.14 & 0.07 & 0.05 \\
\hline 47. & $\beta$-Caryophyllene & 1424 & 3.50 & 4.18 & 4.06 & 3.75 \\
\hline 48. & $\beta$-Copaene & 1430 & - & 0.09 & - & 0.06 \\
\hline 49. & Aromadendrene & 1442 & - & - & - & 0.05 \\
\hline 50 & $\alpha$-Humulene & 1458 & 0.21 & 0.26 & 0.20 & 0.32 \\
\hline 51. & $\alpha$-Elemene & 1465 & 0.13 & 0.09 & 0.08 & 0.19 \\
\hline 52. & $\gamma$-Gurjunene & 1472 & 0.35 & - & - & - \\
\hline 53. & $\gamma$-Muurolene & 1478 & 0.06 & 0.58 & 0.49 & 0.27 \\
\hline 54. & Germacrene D & 1484 & 0.34 & 0.25 & 0.10 & 0.17 \\
\hline 55. & $\alpha$-Muurolene & 1498 & 0.19 & 0.22 & 0.18 & 0.16 \\
\hline 56. & Bicyclogermacrene & 1503 & 0.22 & 0.21 & 0.24 & 0.24 \\
\hline 57. & $\beta$-Bisabolene & 1510 & 0.08 & 0.06 & - & - \\
\hline 58. & $\gamma$-Cadinene & 1518 & 0.63 & 0.68 & 0.73 & 0.97 \\
\hline 59. & $\delta$-Cadinene & 1526 & 0.84 & 0.87 & 0.91 & 0.78 \\
\hline 60 & $\alpha$-Cadinene & 1536 & 0.09 & 0.04 & - & - \\
\hline 61. & $\alpha$-Calacorene & 1541 & 0.06 & 0.07 & 0.05 & 0.06 \\
\hline 62. & Germacrene B & 1558 & 0.11 & 0.07 & - & - \\
\hline 63. & $\beta$-Calacorene & 1562 & - & 0.07 & . & . \\
\hline 64. & Spathulenol & 1581 & - & - & - & 0.11 \\
\hline 65. & Caryophyllene oxide & 1589 & 0.69 & 2.05 & 2.06 & 1.33 \\
\hline 66. & Viridiflorol & 1595 & - & 0.07 & - & - \\
\hline 67. & Tetradecanal & 1614 & - & 0.07 & 0.06 & 0.04 \\
\hline 68. & Humulene epoxide II & 1619 & 0.13 & 0.15 & 0.13 & 0.33 \\
\hline 69. & $\gamma$-Eudesmol & 1626 & 0.41 & 0.16 & 0.25 & - \\
\hline 70. & Isospathulenol & 1630 & 0.13 & - & - & - \\
\hline
\end{tabular}




\begin{tabular}{|c|c|c|c|c|c|c|}
\hline 71. & $\tau$-Cadinol & 1644 & 0.97 & 1.45 & 1.24 & 2.48 \\
\hline 72. & $\alpha$-Cadinol & 1658 & 0.14 & 0.22 & - & 0.20 \\
\hline 73. & $\tau$-Muurolol & 1662 & - & 0.11 & 0.30 & - \\
\hline 74. & 1-Tetradecanol & 1678 & 0.13 & 0.33 & 0.17 & 0.22 \\
\hline 75. & 1-Heptadecene & 1695 & - & - & - & 0.19 \\
\hline 76. & (E,E)-2,6-Farnesyl acetate & 1843 & - & - & - & 0.08 \\
\hline 77. & Diisobutyl phthalate & 1872 & - & - & - & 0.11 \\
\hline 78. & 1-Hexadecanol & 1887 & 0.10 & 0.11 & - & 0.20 \\
\hline 79. & Nonadecane & 1906 & 0.57 & 0.52 & 0.76 & 0.67 \\
\hline 80. & Heptadecanal & 1920 & 0.06 & 0.06 & 0.07 & 0.07 \\
\hline 81. & 2-Methylanthracene & 1931 & - & 0.06 & 0.06 & - \\
\hline 82. & Dibutyl phthalate & 1967 & 0.06 & 0.22 & $\cdot$ & 0.79 \\
\hline 83. & Palmitic acid & 1980 & 0.08 & 0.18 & 0.23 & 0.26 \\
\hline 84. & 1-Heptadecanol & 1983 & 0.07 & 0.08 & 0.17 & - \\
\hline 85. & Eicosane & 2003 & - & 0.08 & 0.09 & 0.16 \\
\hline 86. & 3,3-Dimethylnonadecane & 2042 & - & 0.13 & 0.13 & 0.22 \\
\hline 87. & Heptadecanoic acid & 2065 & - & 0.06 & 0.07 & 0.12 \\
\hline 88. & (E)-Phytol & 2118 & 0.05 & 0.05 & 0.07 & 0.08 \\
\hline 89. & Methyl stearate & 2133 & 0.26 & 0.35 & 0.52 & 0.32 \\
\hline 90. & Linoleic acid & 2138 & 0.37 & 0.73 & 1.21 & 0.75 \\
\hline 91. & Ethyl linoleate & 2157 & 0.18 & 0.28 & 0.53 & 0.30 \\
\hline 92. & Docosane & 2203 & 0.05 & 0.19 & 0.47 & 0.15 \\
\hline \multirow[t]{11}{*}{93.} & 1-Nonacosene & 2893 & - & 0.18 & - & $\cdot$ \\
\hline & Class composition & & & & & \\
\hline & Monoterpene hydrocarbons & & 22.41 & 23.16 & 27.45 & 30.02 \\
\hline & Oxygenated monoterpenes & & 64.01 & 58.67 & 55.17 & 52.39 \\
\hline & Sesquiterpene hydrocarbons & & 7.38 & 8.31 & 7.52 & 7.28 \\
\hline & Oxygenated sesquiterpenes & & 2.47 & 4.21 & 3.98 & 4.45 \\
\hline & Oxygenated diterpenes & & 0.05 & 0.05 & 0.07 & 0.08 \\
\hline & Fatty acids and esters & & 0.89 & 1.60 & 2.56 & 1.75 \\
\hline & Hydrocarbons & & 0.62 & 1.16 & 1.51 & 1.39 \\
\hline & Others & & 1.85 & 2.28 & 1.35 & 2.02 \\
\hline & Total identified & & 99.68 & 99.44 & 99.61 & 99.38 \\
\hline
\end{tabular}

${ }^{a}$ Compounds are listed in order of elution from a HP-5 MS column

${ }^{\mathrm{b}}$ Retention indices relative to $\mathrm{C}_{7}-\mathrm{C}_{30} \mathrm{n}$-alkanes on the HP-5 MS column

$-{ }^{*}$ not detected

Table 4. Statistical analysis of the content of main constituents of essential oils of two Thymus vulgaris L. cultivars

\begin{tabular}{|c|c|c|c|c|c|c|c|c|c|c|c|}
\hline \multirow{2}{*}{$\frac{\text { Cultivar (A) }}{\text { Year of cultivation (B) }}$} & \multicolumn{3}{|c|}{ 'Summer Thyme de Provence' } & \multicolumn{3}{|c|}{ 'English Winter' } & \multicolumn{2}{|c|}{$\begin{array}{l}\text { Mean for the year of } \\
\text { cultivation }\end{array}$} & \multicolumn{3}{|c|}{$\operatorname{LSD}_{\alpha=0.05}$} \\
\hline & 2016 & 2017 & Mean & 2016 & 2017 & Mean & 2016 & 2017 & for $\mathrm{A}$ & for $B$ & $\mathrm{~B} / \mathrm{A}$ \\
\hline 1-Octen-3-ol & $0.52 \pm 0.15$ & $0.34 \pm 0.04$ & 0.43 & $1.03 \pm 0.065$ & $0.85 \pm 0.045$ & 0.94 & 0.775 & 0.595 & 0.115 & 0.155 & n.s. \\
\hline$\beta$-Myrcene & $1.06 \pm 0.075$ & $1.67 \pm 0.10$ & 1.365 & $1.75 \pm 0.075$ & $1.18 \pm 0.045$ & 1.465 & 1.405 & 1.425 & 0.102 & n.s. & 0.144 \\
\hline$\alpha$-Terpinene & $1.67 \pm 0.08$ & $2.49 \pm 0.11$ & 2.08 & $2.27 \pm 0.09$ & $1.77 \pm 0.04$ & 2.02 & 1.97 & 2.13 & n.s. & 0.113 & 0.16 \\
\hline p-Cymene & $15.73 \pm 1.20$ & $11.20 \pm 0.48$ & 13.465 & $7.61 \pm 0.185$ & $10.34 \pm 0.295$ & 8.975 & 11.67 & 10.77 & 0.890 & 0.890 & 1.259 \\
\hline Eucalyptol & $1.48 \pm 0.16$ & $1.26 \pm 0.055$ & 1.37 & $1.24 \pm 0.05$ & $1.22 \pm 0.10$ & 1.23 & 1.36 & 1.24 & 0.133 & n.s. & n.s. \\
\hline$\gamma$-Terpinene & $5.34 \pm 0.27$ & $11.09 \pm 0.75$ & 8.215 & $7.08 \pm 0.12$ & $6.66 \pm 0.16$ & 6.87 & 6.21 & 8.875 & 0.544 & 0.544 & 0.770 \\
\hline cis-Sabinene hydrate & $0.28 \pm 0.015$ & $0.92 \pm 0.06$ & 0.60 & $1.00 \pm 0.01$ & $0.69 \pm 0.10$ & 0.85 & 0.64 & 0.81 & 0.081 & 0.081 & 0.115 \\
\hline Linalool & $3.09 \pm 0.37$ & $2.46 \pm 0.17$ & 2.775 & $2.77 \pm 0.02$ & $3.68 \pm 0.075$ & 3.225 & 2.93 & 3.07 & 0.279 & n.s. & 0.394 \\
\hline Borneol & $2.23 \pm 0.09$ & $1.22 \pm 0.10$ & 1.725 & $0.99 \pm 0.12$ & $1.78 \pm 0.03$ & 1.385 & 1.61 & 1.50 & 0.121 & n.s. & 0.171 \\
\hline Terpinen-4-ol & $1.00 \pm 0.02$ & $1.22 \pm 0.04$ & 1.11 & $0.66 \pm 0.03$ & $1.27 \pm 0.01$ & 0.965 & 0.83 & 1.245 & 0.036 & 0.036 & 0.05 \\
\hline Thymol methyl ether & $0.17 \pm 0.006$ & $0.14 \pm 0.02$ & 0.155 & $2.62 \pm 0.19$ & $0.29 \pm 0.08$ & 1.455 & 1.395 & 0.215 & 0.138 & 0.138 & 0.195 \\
\hline Carvacrol methyl ether & $1.65 \pm 0.09$ & $1.61 \pm 0.09$ & 1.63 & $2.12 \pm 0.17$ & $1.50 \pm 0.02$ & 1.81 & 1.885 & 1.555 & 0.140 & 0.140 & 0.198 \\
\hline Thymol & $36.82 \pm 0.66$ & $37.32 \pm 0.81$ & 37.07 & $44.97 \pm 0.59$ & $38.06 \pm 0.23$ & 41.52 & 40.895 & 37.69 & 0.812 & 0.812 & 1.148 \\
\hline Carvacrol & $6.50 \pm 0.60$ & $5.35 \pm 0.62$ & 5.925 & $5.11 \pm 0.09$ & $8.27 \pm 0.77$ & 6.69 & 5.805 & 6.81 & n.s. & 0.772 & 1.092 \\
\hline$\beta$-Caryophyllene & $4.06 \pm 0.36$ & $3.75 \pm 0.12$ & 3.905 & $3.50 \pm 0.06$ & $4.18 \pm 0.17$ & 3.84 & 3.78 & 3.965 & n.s. & n.s. & 0.395 \\
\hline Caryophyllene oxide & $2.06 \pm 0.08$ & $1.33 \pm 0.14$ & 1.70 & $0.69 \pm 0.006$ & $2.05 \pm 0.26$ & 1.37 & 1.375 & 1.69 & 0.204 & 0.204 & 0.288 \\
\hline$\tau$-Cadinol & $1.24 \pm 0.06$ & $2.48 \pm 0.21$ & 1.86 & $0.97 \pm 0.06$ & $1.45 \pm 0.17$ & 1.21 & 1.10 & 1.96 & 0.188 & 0.188 & 0.266 \\
\hline Linoleic acid & $1.21 \pm 0.13$ & $0.75 \pm 0.13$ & 0.98 & $0.37 \pm 0.02$ & $0.73 \pm 0.075$ & 0.55 & 0.79 & 0.74 & 0.133 & n.s. & 0.188 \\
\hline
\end{tabular}

n.s. - not significant

\pm standard deviation $(\mathrm{n}=3)$

However, its content was significantly higher in the oil obtained from 'English Winter' cultivar (the difference was $4.45 \%)$.

On the other hand, as comparing the results from two years of the study, regardless of thyme cultivar, a significantly higher content of thymol was found in the oil isolated from two-year-old plants as compared with threeyear-old plants - the difference was 3.205\%.

The other components found in significant amount in the investigated oils were: p-cymene, $\gamma$-terpinene, carvacrol and $\beta$-caryophyllene. It was proved that the essential oil obtained from 'Summer Thyme de Provence' cultivar contained more p-cymene and $\gamma$-terpinene, while there was no statistical differentiation in the content of carvacrol and $\beta$-caryophyllene in the essential oils of investigated cultivars. However, when comparing the content of these compounds in dependence on the year of cultivation, significantly higher percentage of p-cymene was noted in the oil extracted from two-year-old plants, while the oil isolated from three-year-old plants was richer in $\gamma$-terpinene and carvacrol. 
834

Thymus vulgaris $\mathrm{L}$. is probably one of the most studied Thymus species from the agronomic point of view due to its wide utilization for industrial purposes (Trindade et al., 2018). Thymol, carvacrol and linalool are considered as the important chemical constituents of thyme herb (Syamasundar et al., 2008). However, the content of thymol in essential oil determines the quality of thyme (StahlBiskup and Saez, 2002).

The chemical composition of thyme's essential oil depends on the several factors, such as environment of growing, development stage (Hudaib and Aburjai, 2007) and chemotypes (Thompson et al., 2003). Literature indicated that thymol, p-cymene, $\gamma$-terpinene, carvacrol, linalool and $\beta$-caryophyllene are ususally reported as the main constituents of thyme essential oil (Thompson et al., 2003; Raal et al., 2005; Hudaib and Aburjai, 2007; Chizzola et al., 2008; Boruga et al., 2014). According to Trindade et al. (2018), thymol chemotype is the most frequent in Thymus vulgaris $\mathrm{L}$.

Our results are in agreement with some other studies (Ozcan and Chalchat, 2004; Zawislak, 2007; Porte et al., 2008; Anzlovar et al., 2014; Boruga et al., 2014; Duscova et al., 2016; Satyal et al., 2016), where thymol, p-cymene, $\gamma$ terpinene and carvacrol were reported to be the major thyme oil components. The essential oil obtained from fresh leaves of T. vulgaris from Brazil (Porte et al., 2008) contained thymol (44.7\%), p-cymene (18.6\%) and $\gamma$ terpinene $(16.5 \%)$ as the main components. In the oils isolated from two varieties of thyme: 'Krajovy' and 'Winter' cultivated in Czech Republic (Duscova et al., 2016), thymol (52.13-61.92\%), o-cymene (11.39-24.86\%) and $\gamma$-terpinene (4.61-13.84\%) were found as the most abundant constituents. Volatile oil isolated from plants collected in Richerenches, France (Satyal et al., 2016) was rich in thymol (47.06\%) and p-cymene $(20.07 \%)$ with lesser quantities of linalool (5.00\%) and carvacrol (3.24\%). Thymol (47.59\%), $\gamma$-terpinene $(30.90 \%)$ and p-cymene $(8.11 \%)$ dominated in the essential oil obtained from T. vulgaris cultivated in Romania (Boruga et al., 2014). The high content of thymol (68.91\%) in volatile oil was found by Anzlovar et al. (2014) in T. vulgaris cv. 'Deutscher winter' cultivated in Slovenia. The other abundant components were p-cymene (13.61\%), $\gamma$-terpinene $(7.60 \%)$, ocimene $(2.11 \%)$ and carvacrol $(1.55 \%)$. In the essential oil obtained from garden thyme cultivated in south-eastern Poland (Zawislak, 2007), thymol (49.9-61.2\%), $\gamma$-terpinene (11.3-12.1\%), p-cymene (9.1$13.5 \%)$ and carvacrol (5.0-6.3\%) were the main components. Thymol (46.2\%), $\gamma$-terpinene (14.1\%), pcymene (9.9\%) and linalool (4.0\%) dominated in the essential oil obtained from $T$. vulgaris growing wild in Turkey (Ozcan and Chalachat, 2004), while in the essential oil isolated from leaves of $T$. vulgaris cultivated in North Yemen (Maqtari et al., 2011) thymol (51.34\%), p-cymene (18.35\%), caryophyllene (4.26\%), $\alpha$-pinene (2.95\%), $\beta$ myrcene $(2.50 \%)$ and carvacrol $(2.03 \%)$ were found in significant amounts.

Interestingly, thymol was not detected in the oil of thyme from Morocco (El Hattabi et al., 2016). Moroccan plants contained mainly carvacrol (78.4\%) and p-cymene (4.6\%) in the essential oil.
The amount of thymol (36.82-44.97\%) detected in our oils was lower as compared to the results obtained by Ozcan and Chalchat (2004), Zawislak (2007), Maqtari et al. (2011), Boruga et al. (2014), Anzlavar et al. (2014), Duscova et al. (2016) and Satyal et al. (2016). However, thymol content was found to be in good agreement with the quality standards of the European Pharmacopoeia (EP limits 36.0-55\%) for thyme oil. Moreover, our cultivars were richer in carvacrol (5.11-8.27\%) in comparison with thyme from France (Satyal et al., 2016), Slovenia (Anzlovar et al., 2014) and North Yemen (Maqtari et al., 2011). Only $T$. vulgaris from Morocco (El Hattabi et al., 2016) had higher content of carvacrol in the essential oil.

The percentage content of $\gamma$-terpinene (5.34-11.09\%) in our essential oil samples was lower than those reported by Ozcan and Chalchat (2004), Zawislak (2007), Porte et al. (2008) and Boruga et al. (2014). However, the content of pcymene (7.61-15.73\%) in our oils was higher than those found in thyme oil from Turkey (Ozcan and Chalchat, 2004) and in garden thyme oil from south-eastern Poland (Zawislak, 2007).

Our results differ from those obtained by Torras et al. (2007) who studied the oil composition of $T$. vulgaris growing wild in Catalonia, in which linalool $(60.55 \%)$ and $\alpha$-terpenyl acetate $(13.95 \%)$ were the main constituents. Similarly, thyme from Southern Italy (De Lisi et al., 2011) was rich in linalool (58.00\%), while plants from Croatia (Jukic and Milos, 2005) contained linalool (40.2-43.0\%), pcymene (13.5-15.5\%) and 1,4-terpineol (4.3-6.8\%) in the essential oil.

The content of linalool in our T. vulgaris cultivars varied from 2.77 to $3.68 \%$, while the content of terpinen-4-ol (1,4terpineol) did not exceed $1.27 \%$. We not detected $\alpha$ terpenyl acetate in our oils.

The major constituents of the essential oils isolated from T. vulgaris cultivars: 'English Winter' and 'Summer Thyme de Provence' were thymol, p-cymene and $\gamma$-terpinene, which suggest that the analyzed oils belong to the thymol chemotype.

\section{Conclusions}

Both examined Thymus vulgaris $\mathrm{L}$. cultivars belong to the thymol chemotype, with differences in the concentration of p-cymene and $\gamma$-terpinene. The higher content of p-cymene and $\gamma$-terpinene we noted in 'Summer Thyme de Provence' cultivar, while 'English Winter' cultivar was richer in thymol. Based on these results we suppose that the isolated essential oils will exhibit good antioxidant and antimicrobial properties. Moreover, both cultivars can found wide application in food industry as flavor ingredients to beverages and confectionary products as well as in cosmetic industry as natural preservatives.

\section{References}

Adams RP (2007). Identification of essential oil components by gas chromatography/mass spectrometry, 4th ed. Allured Publishing Corporation, Carol Stream, Illinois USA.

Agili FA (2014). Chemical composition, antioxidant and antitumor activity 
of Thymus vulgaris L. essential oil. Middle-East Journal of Scientific Research 21(10):1670-1676.

Al-Asmari AK, Athar MT, Al-Faraidy AA, Almuhaiza MS (2017). Chemical composition of essential oil of Thymus vulgaris collected from Saudi Arabian market. Asian Pacific Journal of Tropical Biomedicine $7(2): 147-150$.

Alizadeh A (2013). Essential oil constituents, phenolic content and antioxidant activity in Iranian and British Thymus vulgaris $\mathrm{L}$. International Journal of Agriculture and CropSciences 6(4):213-218.

Anzlovar S, Baricevic D, Avgustin JA, Koce JD (2014). Essential oil of common thyme as a natural antimicrobial food additive. Food Technology and Biotechnology 52(2):263-268.

Babushok VI, Linstrom PJ, Zenkevich IG (2011). Retention indices for frequently reported compounds of plant essential oils. Journal of Physical and Chemical Reference Data 40 (4):1-47.

Boruga O, Jianu C, Misca C, Golet I, Gruia AT, Horhat FG (2014). Thymus vulgaris essential oil: chemical composition and antimicrobial activity.Journal of Medicine and Life 7(3):56-60.

Carlen C, Schaller M, Carron CA, VouillamozJF, Baroffio CA (2010). The new Thymus vulgaris L. hybrid cultivar 'Varico 3' compared to five established cultivars for Germany, France and Switzerland. Acta Horticulturae 860:161-166.

Chizzola R, Michitsch H, Franz C (2008). Antioxidant properties of Thymus vulgaris leaves: Comparison of different extracts and essential oil chemotypes. Journal of Agricultural and Food Chemistry 56(16):68976904.

Cornara L, La Rocca A, Marsili S, Mariotti MG (2000). Traditional uses of plants in the eastern Riviera (Liguria, Italy). Journal of Ethnopharmacology 125(1):16-30.

De Lisi A, Tedone L, Montesano V, Sarli G, Negro D (2011). Chemical characterisation of Thymus populations belonging from Southern Italy. Food Chemistry 125(4):1284-1286.

Duskova E, Dusek K, Smekalova K, Nosalkova M, Benicka S(2016). ESL 2: Genetic resources of Thymus vulgaris $\mathrm{L}$. and $T$. vulgaris $\mathrm{x} T$. Marschallianus Willd. in the Czech Republic. In: $6^{\text {th }}$ International Symposium Breeding Research on Medicinal and Aromatic Plants, BREEDMAP 6, Quedlingburg, Germany pp 56-58.

El Hattabi L, Talbaoui A, Amzazi S, Bakri Y, Harhar H, Costa J, ... Tabyaoui M (2016). Chemical composition and antibacterial activity of three essential oils from south of Morocco (Thymus satureoides, Thymus vulgaris and Chamaelum nobilis). Journal of Materials and Environmental Science 7(9):3110-3117.

European Pharmacopoeia 7.0 (2010). Strasbourg, Council of Europe pp 1252-1254.

Filipiak K, Wilkos S (1995). Statistical calculations. Description of the AWARsystem. IUNG, Puławy R 324:1-52 [in Polish].

Guillen MD, Manzanos MJ (1998). Study of the composition of the different parts of a Spanish Thymus vulgaris L. plant. Food Chemistry 63(3):373-383.

Hudaib M, Aburjai T (2007). Volatile components of Thymus vulgaris L. from wild-growing and cultivated plants in Jordan. Flavour and Fragrance Journal 22(4):322-327.
Jukic M, Milos M (2005). Catalystic oxidation and antioxidant properties of thyme essential oils (Thymus vulgarae L.). Croatica Chemica Acta 78(1):105-110.

Marino M, Bersani C, ComiG(1999). Antimicrobial activity of the essential oils of Thymus vulgaris $\mathrm{L}$. measured using a bioimpedometric method. Journal of Food Protection 62(9):1017-1023.

Marzec M, Polakowski C, Chilczuk R, Kolodziej B (2010). Evaluation of essential oil content, its chemical composition and price of thyme (Thymus vulgaris L.) raw material available in Poland. Herba Polonica 56(3):37-52.

Maqtari MAA, Alghalibi SM, Alhamzy EH (2011). Chemical composition and antimicrobial activity of essential oil of Thymus vulgaris from Yemen. Turkish Journal of Biochemistry 36(4):342-349.

Ozcan M, Chalchat J-C (2004). Aroma profile of Thymus vulgaris L. growing wild in Turkey. Bulgarian Journal of Plant Physiology 30(34):68-73.

Ozguven M, Tansi S (1998). Drugyield and essential oil of Thymus vulgaris L. as in influenced by ecological and ontogenetical variation. Turkish Journal of Agriculture and Forestry 22(6):537-542.

Porte A, Ronoel L, Godoy O (2008). Chemical composition of Thymus vulgaris L. (thyme) essential oil from Rio de Janeiro State (Brazil). Journal of the Serbian Chemical Society 73(3):307-310.

Raal A, Arak E, Orav A (2005). Comparative chemical composition of the essential oil of Thymus vulgaris L. from different geographical sources. Herba Polonica 1(2):10-17.

Satyal P, Murray BL, McFeeters RL, Setzer WN (2016). Essential oil characterization of Thymus vulgaris from various geographical locations. Foods 5(70):1-12.

Sharafzadeh S, Khosh-Khui M, Javidnia K, Alizadeh O, Ordookhani K (2010). Identification and comparison of essential oil components in leaf and stem of garden thyme grown under greenhouse conditions. Advances in Environmental Biology 4(3):520-523.

Stahl-Biskup E, Saez F (2002). Thyme: the genus Thymus. Taylor \& Francis, London.

Syamasundar KV, Srinivasulu B, Stephen A, Ramesh S, Rao RR (2008). Chemical composition of volatile oil of Thymus vulgaris $\mathrm{L}$. from Western Ghats of India. Journal of Spices and Aromatic Crops 17(3):255-258.

Thompson JD, Chalchat JC, Michet A, Linhart YB, Ehlers B (2003). Qualitative and quantitative variation on monoterpene co-occurrence and composition in the essential oil of Thymus vulgaris chemotypes. Journal ofChemical Ecology 29(4):859-880.

Torras J, Grau MD, Lopez JF, de las Heras FX (2007). Analysis of essential oils from chemotypes of Thymus vulgaris in Catalonia. Journal of the Science of Food and Agriculture 87(12):2327-2333.

Trindade H, Pedro LG, Figueiredo AC, Barroso JG (2018). Chemotypes and terpene synthase genes in Thymus genus: State of the art. Industrial Crops \& Products 124:530-547.

Zawislak G (2007). Analysis of chemical composition of essential oil in the herb of thyme (Thymus vulgaris L.) grown in south-eastern Poland. Herba Polonica 53(3):241-245. 